\title{
Língua Portuguesa: formação docente e educação pré-escolar em contexto timorense
}

\author{
Márcia Vandineide Cavalcante ${ }^{*}$ \\ Regina Pires Brito**
}

\section{Resumo}

Desde o período da Administração Transitória das Nações Unidas em Timor-Leste diversos são os programas de cooperação do Brasil e de Portugal para a difusão e ensino da Língua Portuguesa (LP) naquele país. É o caso, por exemplo, do Programa de Qualificação Docente e Ensino de Língua Portuguesa em Timor-Leste, promovido pela Coordenação de Aperfeiçoamento de Pessoal de Nível Superior. Nesse sentido, na confluência das áreas de Educação (numa perspectiva freireana) e dos Estudos Lusófonos, após breve contextualização da situação da LP em Timor-Leste (no período colonial e durante o domínio indonésio), este artigo, com base em memoriais elaborados pelos participantes do Curso de Português Instrumental (CPI), inserido no Projeto de Ensino da Língua Portuguesa Instrumental, analisa alguns aspectos do trabalho realizado no âmbito desse Curso dirigido a professores da pré-escola de Díli. Destacam-se, aqui, a percepção dos educadores quanto à contribuição do CPI e às atividades propostas, visando tanto a fluência na expressão em português quanto, e principalmente, uma produtiva prática pedagógica e o processo de conscientização dos docentes em relação à necessidade do domínio da Língua Portuguesa.

Palavras-chave: Ensino de Língua Portuguesa. Formação Docente. Timor-Leste.

\footnotetext{
* Mestra em Letras pela Universidade Presbiteriana Mackenzie (UPM).

*** Doutora em Linguística pela Universidade de São Paulo (USP). Professora da Pós-Graduação em Letras da Universidade Presbiteriana Mackenzie (UPM).
} 
As palavras na cartilha, r-o-ro-l-a-la e dizia lakateu em tétum porque era o lakateu que lá estava configurado. Era o lakateu que eu guardava na minha cabeça e no meu bolso, apanhado em perseguições dolorosas na altura das chuvadas, e que de asas molhadas e cansadas desistia facilmente. G-a-ga-l-o-lo e dizia manu-aman em tétum porque era o manu-aman que estava pintado sem as cores festivas das lutas de galo aos domingos no bazar. (CARDOSO, 2002, p. 37).

\section{Considerações iniciais}

Durante o período colonial português em Timor-Leste, a língua de administração e de ensino foi a Língua Portuguesa (LP). Apesar disso, só uma minoria falava Português, pois o acesso às poucas escolas era restrito, como registra Thomaz (2002, p. 138) apenas “em 1915 se abriu a primeira escola oficial em Díli”, até então as escolas existentes eram dirigidas pelas dioceses, com limitada quantidade de vagas. O sistema de ensino dessa época exigia que o estudante se expressasse somente em português, recebendo punições caso usasse sua língua materna em sala de aula. O trecho abaixo, extraído do romance autobiográfico "Crônicas de uma Travessia”, do timorense Luís Cardoso (2002) (de onde também extraímos a epígrafe que abre este artigo ${ }^{1}$ ), é ilustrativo dessa situação, mencionando a obrigatoriedade do uso do português, os castigos impostos e criando a metafórica figura do "guarda linguístico":

Embora a escola fosse um local erigido no meio daquelas colinas, como um altar de sabedoria, com gente oriunda de diversas etnias e falantes de diferentes idiomas, o português era obrigatório, e sancionado com reguadas quem transgredisse essa norma. $\mathrm{O}$ efeito da mandioca seca ou da reguada era fustigante mas eficaz. Durante o dia a palmatória circulava de mão em mão através de sentinelas, ou guardas linguísticos, por vezes armavam ciladas como forma de se livrarem rapidamente do testemunho. (CARDOSO, 2002, p. 53-54).

A proibição e as sanções para quem falasse as línguas locais eram mais comuns nos externatos, mas nas demais escolas o ensino também só era realizado em Língua Portuguesa. A educação escolar, portanto, além de atender somente uma minoria da população, ignorava a riqueza geográfica, histórica, cultural e linguística de Timor-Leste. Um excerto do romance histórico Colibere, de Domingos de Sousa (2007), ao descrever o livro didático utilizado pela personagem Colibere, registra essa falta de vinculação com o cotidiano timorense: 
Não havia retratos de timorenses. Quanto aos animais havia vários que ele conhecia e outros que ele nunca tinha visto na vida como leão, tigre, hipopótamo, zebra, hiena, girafa, etc. Colibere ficou espantado quando se deparou com a figura da girafa. Achava graça como um animal podia ter um pescoço tão comprido. (SOUSA, 2007, p. 50).

Esta referência, somada aos trechos transcritos do romance de Luís Cardoso (2002), revela como era comum o uso nas colônias de material didático vindo de Portugal, distante da realidade local - fato que não é específico de Timor, nem muito diferente de outras situações colonizatórias. Vale lembrar que a evangelização foi a raiz de fixação portuguesa na ilha, iniciada com os primeiros missionários em meados do século XVI. Somente no início do século XVII, com a nomeação de Antonio Coelho Guerreiro como primeiro governador português, inicia-se uma administração "indireta" dos diferentes reinos que compunham o espaço timorense, que se prolonga até fins do século XIX. Apenas em meados do século XX é que se estabelecem as divisões administrativas definitivas, mas nunca houve grandes investimentos para a colonização de Timor-Leste, por vários motivos, desde as dificuldades de deslocamento e de recrutamento de colonos até o interesse centrado em outras colônias.

Apesar disso, as línguas locais e, principalmente, o tétum - língua veicular falada por todo o país desde antes da chegada dos portugueses - foram aos poucos incorporando elementos da LP (especialmente no plano lexical) ao mesmo tempo em que também a alimentaram. Evidentemente, o português era a língua da administração, das atividades culturais e da instrução, predominantemente na modalidade escrita; já o tétum era a língua majoritária na comunicação cotidiana entre pessoas de diferentes línguas maternas (BRITO, 2013). Na verdade, a parceria histórica que se estabeleceu entre o português e o tétum propiciou sobremaneira o fortalecimento do tétum (CORTE-REAL; BRITO, 2006). Quanto a isto, vale a afirmação da direção do Instituto Nacional de Linguística de Timor Lorosa'e (INL), em entrevista concedida ao jornal local Semanário de Timor-Leste, de 30 de agosto de 2003:

[...] conhecendo a história de Timor, podemos dizer que se não houvesse a língua portuguesa, não teria havido um idioma chamado tétum-praça - que encontrou no Português uma fonte nos aspectos fonológicos (sistema de sons), morfológicos (formação de palavras), sintácticos (construção das frases), semânticos (atribuição dos significados), pragmáticos (uso prático), mentais e culturais (estrutura do pensamento e hábitos ou processos).

Desse modo, uma presença forte e significativa da língua portuguesa até a independência (28 de novembro de 1975) não se deu, considerando a totalidade do território e a quantidade de timorenses 
falantes. No entanto, em 7 de dezembro de 1975, a Indonésia, com apoio velado dos Estados Unidos, anexou, numa invasão violenta, Timor-Leste ao seu território num incurso que durou até 1999.

Nos anos que antecederam os acontecimentos históricos de 1974 e 1975 - Revolução dos Cravos, Independência das Colônias Portuguesas e, em Timor-Leste, início do domínio indonésio -, ainda que se perceba tímida elevação na taxa de escolarização e na aprendizagem da LP, "o Português não chegou, pois, a tornar-se em Timor a língua normal da comunicação oral” (THOMAZ, 2002, p. 140), nem mesmo se tornou língua de contato entre grupos distintos - papel que sempre coube ao tétum. O português, pontua Brito (2010, p. 183):

[...] manteve, via de regra, o caráter de língua clerical, administrativa e de cultura; embora sua função seja relevante no plano interno, articulando a unidade cultural por meio de uma pequena elite de letrados nativos e, no plano externo, procurando associar a cultura local ao universo lusíada.

Durante o período indonésio (1975-1999), Timor-Leste sofreu um processo de "destimorização", que incluiu a imposição da língua indonésia, a minimização da utilização do tétum e a proibição do uso do português, que permaneceu formalmente apenas no Externato São José e clandestinamente nas montanhas e em algumas organizações católicas na capital. Com o ensino oficial todo ministrado em língua indonésia, muitas escolas foram abertas e se estabeleceram programas efetivos de ensino desse idioma, até então desconhecido pelos timorenses. Nesse período, mais de 6 mil professores indonésios passaram a integrar o corpo docente das escolas de ensino básico em TimorLeste, revelando o esforço do invasor para a implantação de sua língua, e destacando-se o fato de que, à medida que os timorenses aprendiam a língua indonésia, alguns eram imediatamente recrutados para atuarem como professores.

Apesar da tentativa de "destimorização", manifestada na perseguição aos valores tradicionais timorenses, nas dificuldades impostas aos rituais da fé cristã e, como dissemos, na proibição da língua portuguesa do espaço timorense, o português passou a ser fundamental contra o invasor no processo de resistência. Da mesma forma, o tétum foi bastante fortalecido, pois, preservando seu papel de língua integradora, era a mais utilizada pelo movimento de resistência formado por grupos falantes de diferentes línguas locais, além de ter sido um caminho utilizado pela igreja católica ao traduzir textos litúrgicos para esse idioma.

Considerando a história de opressão no período indonésio em relação ao uso da LP, bem como o restrito acesso ao seu aprendizado no período português, faz-se necessário pensar na relevância do 
ensino contextualizado de LP hoje, no país independente, onde figura como língua oficial ao lado do tétum. Há um caminho em via de mão dupla em que tanto o Português contribui para a descrição e o fortalecimento das línguas locais, especialmente da Língua Tétum, quanto a variedade do português timorense vai definindo suas especificidades e se enriquecendo de elementos locais, nos diferentes planos (fonético-fonológico, morfológico, sintático e lexical). Este é o cenário que enseja, em TimorLeste, há mais de uma década, ações de cooperação internacional voltadas para a difusão do português e para a aplicação de metodologias de ensino adequadas, como a experiência que aqui se relata.

Concebendo, como Paulo Freire (2003, p. 46), a educação como prática permanente, contextualizada e dialógica, todas as ações desenvolvidas em parceria com os timorenses não podem perder de vista o fato de que toda a práxis está circunscrita a certos limites propostos pelos sujeitos aos quais cada atuação se destina:

A prática que é social e histórica, mesmo que tenha uma dimensão individual, se dá num certo contexto tempo-espacial e não na intimidade das cabeças das gentes [...]. A compreensão dos limites da prática educativa demanda indiscutivelmente a claridade política dos educadores com relação ao seu projeto. Demanda que o educador assuma a politicidade de sua prática [...].

Com esse olhar pautado numa (educ)ação dialógica, que crê na prática significativa e não impositiva, é que acreditamos ser imprescindível o esforço conjunto da comunidade dos países de língua portuguesa para a concretização de um espaço "lusófono"2 democrático, voltado para o desenvolvimento cientifico, tecnológico e cultural das comunidades, pautado no respeito e no (re)conhecimento mútuos. Nessa perspectiva, portanto, assumimos que a ideia de lusofonia:

[...] tem que ser um pouco de todos, por todos e para todos, sem ser, exclusivamente, de ninguém. [...] carece de uma convergência de intenções e de ações que tanto permitam a expansão do português pelo mundo, quanto (e principalmente) que viabilizem a difusão no âmbito circunscrito da chamada comunidade lusófona. Essa difusão interna, contudo, passa, necessariamente pelo estudo das identidades linguísticas, históricas e culturais de cada espaço, o que representa conhecer e legitimar o papel que, individualmente o português representa e a função que exerce nas diferentes realidades onde se faz presente. [...] Na lusofonia que verdadeiramente deva interessar aos povos que partilham língua e traços de história e de cultura comuns, não há lugar nem para anacronias imperialistas, para posturas neocolonialistas, para protagonismos ou representações preconceituosas. [...] a lusofonia que faz sentido é a lusofonia da comunidade do respeito mútuo. (BRITO, 2013, p. 122-123). 


\section{O ensino de Língua Portuguesa para professores da Pré-Escola de Díli}

Com a restauração da independência em 20 de maio de 2002 (após o período de Administração Transitória das Nações Unidas - 1999 a 2002), estabelece-se constitucionalmente a oficialidade das línguas portuguesa e tétum, fomentando investimentos visando à sensibilização para a comunicação em LP, a estratégias de ensino eficazes e contextualizadas e de padronização ortográfica e normatização da língua tétum (realizado pelo INL). Assim, diversos são os programas de cooperação do Brasil e de Portugal em vigência pelo país. É o caso do Programa de Qualificação Docente e Ensino de Língua Portuguesa em Timor-Leste (PQLP), promovido pela Coordenação de Aperfeiçoamento de Pessoal de Nível Superior (CAPES), que possibilitou a vivência aqui relatada.

Com efeito, este artigo apresenta um recorte descritivo do Curso de Português Instrumental (CPI), dirigido aos professores da Educação Pré-Escolar de Díli, no âmbito de um dos projetos do PQLP/CAPES, denominado Ensino da Língua Portuguesa Instrumental (ELPI), ação destinada a professores, pessoal administrativo, técnicos e dirigentes da Universidade Nacional Timor Lorosa'e (UNTL) e do Ministério da Educação (ME).

A criação do CPI específico para professores do Ensino Pré-Escolar foi uma demanda apresentada pelo ME/Timor, diante da necessidade de proficiência em LP desses educadores. A falta de domínio da LP é sério entrave para o desenvolvimento profissional docente, pois, de acordo com a Lei $n^{\circ}$ 14, de 29 de outubro 2008, Lei de Base da Educação de Timor-Leste, Artigo 57 : “ “A partir do ano letivo de 2010 apenas poderão integrar o sistema educativo timorense os estabelecimentos de educação e de ensino que utilizem como língua de ensino as línguas oficiais de Timor-Leste" (TIMOR-LESTE, 2008). Em outras palavras, para que esses estabelecimentos estejam de acordo com a legislação, os professores devem dominar o tétum e o português.

De início, o CPI objetivava apenas o ensino de LP, contudo, logo de início, os professores solicitaram a inclusão de atividades de formação que os auxiliassem na sua prática pedagógica. Desse modo, o Curso passou a oferecer também ferramentas metodológicas que pudessem contribuir para a prática pedagógica. Ressalte-se que a língua de alfabetização em Díli é o tétum ${ }^{3}$, porém, quando da realização do CPI, o Currículo era bilíngue e a maior parte dos professores desenvolvia na Pré-Escola algum tipo de atividade envolvendo a LP, especialmente atividades relacionadas à prática de oralidade. 
O relato de experiência do CPI pode trazer informações relevantes para o desenvolvimento de ações direcionadas ao ensino de português em Timor-Leste, atentando para àquelas que contribuíram para o desenvolvimento do aprendizado da LP do grupo envolvido. Sendo assim, este artigo, na confluência das áreas de Educação e dos Estudos Lusófonos, focalizando o ensino de Português, objetiva, a partir da análise de memoriais produzidos por participantes do CPI, verificar em que medida o Curso se tornou relevante para os docentes em relação ao aprendizado da LP e em sua prática pedagógica. Para tanto, serão observadas: (1) a impressão dos professores quanto à contribuição do CPI ou de atividades realizadas durante o seu processo para fluência na comunicação em LP; (2) a conscientização da importância do CPI para a formação docente e para a prática pedagógica.

Todo o processo de construção do CPI se deu por meio de atividades conjuntas com os professores, com quem foram discutidos os princípios para o encaminhamento do Curso (do conteúdo programático até as atividades pedagógicas). Assim, partimos do atendimento às necessidades imediatas apontadas pelos participantes, considerando o ensino da língua numa dimensão interacional e dialógica, construídas e conduzidas conjuntamente por timorenses e brasileiros. Para tanto, a estruturação do Curso nasceu do contexto sócio-histórico-cultural e linguístico local, noção e valorização das necessidades apontadas e do respeito e da consciência de que se está diante de uma variedade do português específica, o português timorense (BRITO, 2010, 2012, 2013).

Nesse sentido, a análise que ora se apresenta se dá numa perspectiva freireana de educação, compreendida como ajuda autêntica:

[...] aquela em cuja prática os que nela se envolvem se ajudam mutuamente, crescendo juntos no esforço comum de conhecer a realidade que buscam transformar. Somente numa tal prática, em que os que ajudam e os que são ajudados se ajudam simultaneamente, é que o ato de ajudar não se distorce em dominação de quem ajuda sobre quem é ajudado. (FREIRE, 1978, p. 15).

O CPI iniciou-se em fevereiro de 2008, com uma turma de 14 participantes. Posteriormente, com o aumento do número de professores, passou a ser estruturado em três níveis: básico, intermediário e avançado. Ao final de 2010, atingiu 107 alunos, oriundos de 28 escolas, de um total de 31 Pré-Escolas existentes na capital do país naquele período. Devido ao aumento da procura pelo Curso e à autonomia que vinha sendo desenvolvida por parte dos participantes, os professores com maior proficiência na LP (já no nível avançado) passaram a atuar como monitores das demais turmas.

Para o recorte aqui apresentado, adotou-se como metodologia o relato de experiência, recorrendo a uma amostra de produtos de 22 profissionais da Educação Pré-Escolar de Díli, integrantes 
da turma do nível avançado do CPI. Desses, 19 são professores; dois (2) são professores e diretores de pré-escolas da capital; uma (1) é funcionária do ME/Timor. A faixa etária varia dos 20 aos 60 anos (no caso timorense, a faixa etária determina em que língua teve sua educação formal), sendo $86 \%$ do sexo feminino. Verificou-se que $54 \%$ dos sujeitos tiveram sua educação formal em LP, ainda durante o período português, e $46 \%$ em língua indonésia, durante o domínio indonésio. Os que estudaram no período indonésio tiveram maiores oportunidades de concluir o Ensino Secundário, porém com menos (ou nenhum) acesso ao ensino de LP. Nenhum deles tinha nível universitário e todos dominavam a modalidade oral do tétum, apesar de não conhecerem adequadamente a ortografia oficial dessa língua. $\mathrm{Na}$ verdade, apesar de alfabetizarem as crianças em tétum, só recentemente, com a elaboração de gramáticas e do guia ortográfico oficial, essa língua passou a ser ministrada nas instituições de ensino.

A maioria dos participantes só assumiu a função de professor após 1999, com o fim do período indonésio, tendo sido o conhecimento de LP que possuíam um dos fatores que levou vários a se tornarem docentes, como é o caso dos que estudaram no período colonial português. Os professores que nunca haviam estudado sistematicamente Português antes do CPI, e começaram a lecionar após a independência, utilizavam a língua tétum como língua de ensino. Essa diversidade de experiências dos participantes se mostrou enriquecedora, revelada pela atuação empolgada e pelo interesse constante de todos no desempenho das atividades.

A situação funcional dos participantes do CPI, nos três grupos, era semelhante. Havia funcionários permanentes do Estado, professores com contrato temporário e muitos voluntários, cujo salário dependia dos valores mensais pagos pelos pais dos alunos. Não havia qualquer incentivo financeiro para participar do Curso; contudo, todos se empenhavam em aprender ou aperfeiçoar a LP, sendo assíduos e ativos durante todo o processo.

O critério de escolha da turma do nível avançado como amostragem deveu-se ao fato de a maioria, $82 \%$, ter ingressado desde o primeiro ano do curso (2008), permanecendo, assim, mais tempo como integrantes do CPI (até 2010) e também por ser essa a única turma que elaborava o memorial, documento escolhido para análise. O corpus aqui apresentado constitui-se de trechos de memoriais de quatro professores, participantes da turma de avançado, recolhidos durante o ano de 2010.

Para a compreensão de algumas especificidades da metodologia adotada, apresenta-se, a seguir, sinteticamente, o processo de estruturação didático-pedagógica do Curso, compreendendo o contexto da educação Pré-Escolar de Díli. 


\section{Descrição didático-pedagógica do CPI}

À medida que foram conhecidas as motivações e interesses específicos dos professores da Educação Pré-Escolar, percebeu-se a necessidade de elaboração de uma estrutura didático-pedagógica do CPI particular para aquele grupo. Buscar conhecer o contexto histórico do ensino da LP em TimorLeste, considerando as necessidades apontadas por aqueles alunos-professores, coaduna-se com o pensamento de Freire (1978), ao tratar dos projetos educacionais em que estava envolvido em GuinéBissau:

Nossa colaboração ao desenho do projeto e à posta em prática do mesmo dependeria de nossa capacidade de conhecer melhor a realidade nacional, aprofundando o que já sabíamos em torno da luta pela libertação. [...] cujo desenho e processo podemos dar nossa colaboração, na medida em que começamos a conhecer melhor a realidade do país. (FREIRE, 1978, p.16; 94).

A programação do Curso, feita com os participantes e não simplesmente para eles, reflete uma posição que retoma em Freire (1978, p. 19), ao relatar qual seria a sua postura, ainda em Genebra, quando chegasse a Guiné-Bissau: “daí que tenhamos deixado Genebra dispostos a ver e a ouvir; a indagar e a discutir e não carregando conosco, em nossas valises de mão, planos salvadores ou relatórios semi-elaborados". Nesse sentido, a coparticipação dos alunos-professores no planejamento e na execução do CPI é apontada como aspecto inovador e positivo para a atuação docente, além de facilitadora do aprendizado da LP, posto que o Curso abordava temas utilizados de imediato no cotidiano de sala de aula.

Nas reuniões de planejamento e de discussão sobre o CPI, percebeu-se que o Curso poderia estabelecer vínculos entre o aprendizado da LP e a Educação Pré-Escolar em Díli. Essa ponte entre o ensino de português e a prática pedagógica alertou para a necessidade de se adotar uma metodologia que considerasse comparações estabelecidas entre o tétum e o português. Após discutir sobre os conteúdos do CPI e conhecer os conteúdos trabalhados nas aulas da Pré-Escola, tendo por base o currículo bilíngue proposto pelo ME/Timor, decidiu-se, em conjunto, elaborar um plano de Curso a partir dos temas propostos no currículo da Pré-Escola, já conhecidos e utilizados por eles.

Como dito, no segundo ano do CPI, dado o crescente número de interessados, integrantes do avançado passaram a atuar como monitores junto aos colegas dos níveis básico e intermediário. Com a monitoria, procurou-se o aumento da autoconfiança desses docentes, visando à sua autonomia, conforme a perspectiva freireana: 
Autonomia enquanto amadurecimento do ser para si é processo, é vir a ser. Não ocorre em data marcada. É neste sentido que uma pedagogia da autonomia tem de estar centrada em experiências da decisão e da responsabilidade, vale dizer, em experiências respeitosas da liberdade (FREIRE, 1996 apud VASCONCELOS; BRITO, 2006, p. 50).

Nessa experiência de desenvolvimento da autonomia, o grupo de monitores demonstrou compromisso e interesse pela atividade e, constantemente, mensurava a sua participação como positiva, tanto contribuindo para o aprendizado dos colegas quanto percebendo que estavam aprendendo mais ao exercerem o papel de monitores. Essa forma participativa de construção do programa do CPI propiciou o entendimento de que o Curso estava sendo construído com eles, por ser deles, e não simplesmente para eles: “a investigação do pensar do povo não pode ser feita sem o povo, mas com ele, como sujeito de seu pensar" (FREIRE, 2011, p. 140). Em qualquer contexto, nunca pensar pelo outro e sim com o outro, certamente é o caminho mais adequado quando a intenção é o desenvolvimento e a autonomia aspectos fundamentais em projetos pedagógicos.

Outro fator importante para a estruturação didático-pedagógica foram as visitas de acompanhamento da prática pedagógica que realizávamos nas escolas dos participantes do Curso. Essas visitas tinham caráter observacional da realidade de trabalho dos alunos do CPI, verificando se havia reflexos do Curso na prática docente. A partir dessa observação, atividades foram acrescentadas ao Curso, visando atender às necessidades didático-pedagógicas específicas verificadas in loco.

Em 2010, terceiro ano do Curso, a demanda de participantes cresceu ainda mais e o Curso foi reconhecido pelo Instituto Nacional de Formação Profissional Contínua (INFPC) - atualmente Instituto de Formação de Docentes e Profissionais da Educação (INFORDEPE) - e pelo ME/Timor. Dessa maneira, a certificação do Curso passou a ser importante também para a progressão profissional dos professores que eram servidores públicos. Nesse período, o CPI assim se estruturava:

- duas vezes por semana, com aulas abordando aspectos de compreensão auditiva, leitura, escrita e estrutura da língua;

- uma vez por semana, com reforço coletivo, juntando as três turmas;

- uma vez por semana, desenvolvendo oficinas gerais e oficinas específicas para monitores;

- uma vez por semana, com aulas de reforço específicas para a turma de avançado;

- uma vez por mês, com reunião de planejamento com os monitores. 


\section{As aulas}

Ainda que aspectos formais e normativos da Língua Portuguesa integrassem cada tema, as aulas desenvolviam-se a partir do currículo da Educação Básica e não em função de tópicos gramaticais, que eram introduzidos paulatinamente ao longo das aulas. Dessa forma, os participantes aprendiam elementos da Língua Portuguesa a partir dos conteúdos significativos e dos quais necessitariam para o exercício cotidiano com as crianças, possibilitando um aprendizado contextualizado.

\section{Aulas de reforço}

Imagem 1 - Aula de reforço com o tema "amizade", ministrada por grupo de alunos dos três níveis - 2010

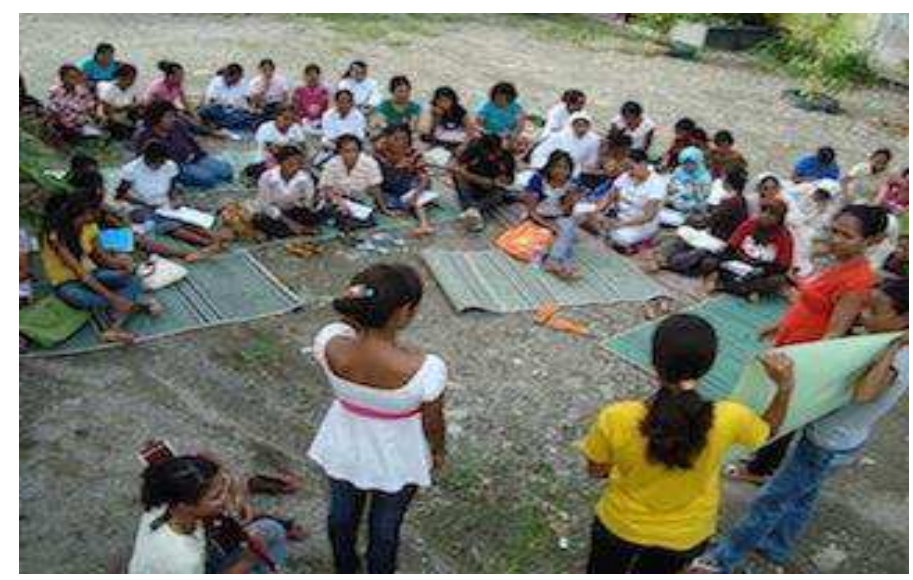

Fonte: Márcia V. Cavalcante, 2010.

Adotava-se, nas aulas de reforço, uma metodologia diferenciada das aulas regulares, procurando-se usar jogos e dinâmicas como forma de fixação de conteúdos. Por decisão dos integrantes do Curso, o reforço coletivo das terças-feiras passou a ser ministrado por alunos dos três níveis, com a liderança dos monitores. Para isso, semanalmente, um dos temas do currículo era escolhido para ser apresentado por meio da aula simulada, uma dinâmica que fazia com que atuassem como se estivessem diante de seus alunos; por isso, muitas vezes, realizavam atividades bilíngues em tétum e em português, considerando a realidade da Educação Pré-Escolar de Díli.

\section{Oficinas Pedagógicas}

As oficinas pedagógicas ocorriam semanalmente com os monitores que, posteriormente, as ministrariam para os demais grupos. Consistiam em: a) confecção de recursos pedagógicos relacionados aos temas trabalhados nas aulas, utilizando material de sucata (procurando contornar a 
limitada disponibilidade de materiais); b) aprendizado de música e brincadeiras para ampliação do vocabulário em LP; c) resgate e registro de músicas, jogos e brincadeiras timorenses; d) uso de músicas, jogos e brincadeiras brasileiras e portuguesas, objetivando o contato com aspectos de outras culturas lusófonas; e) resgate e registro de histórias tradicionais timorenses, ouvidas pelos professores na infância.

Professores, coordenadores e diretores da Pré-Escola não integrantes do CPI, mas que trabalhavam nas escolas em que havia participante do Curso, poderiam tomar parte das oficinas, favorecendo a realização de atividades desenvolvidas com seus alunos. Essas oficinas conferiram ao Curso um caráter prático, lúdico e integrador.

\section{Imagem 2 - Oficinas pedagógicas}
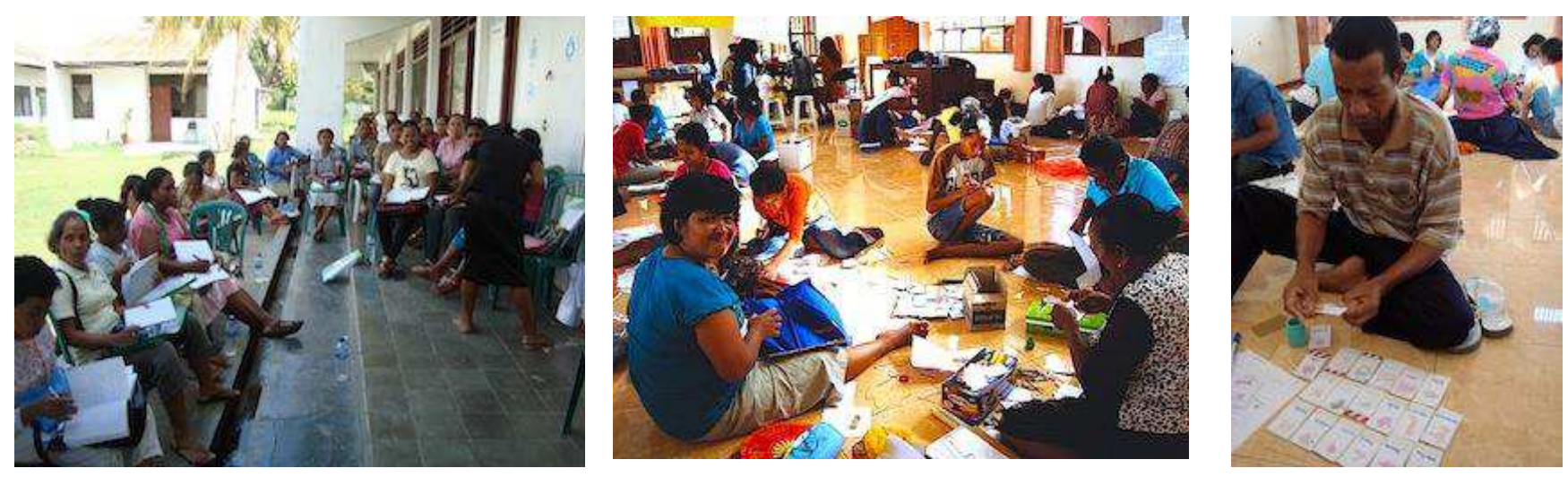

Fonte: Márcia V. Cavalcante, 2010.

A participação cada vez mais efetiva dos professores proporcionou-lhes maior autonomia, fator indispensável no processo ensino-aprendizagem, como lembra Freire (2011, p. 91): “É com ela, a autonomia, penosamente construindo-se, que a liberdade vai preenchendo o 'espaço' antes 'habitado' por sua dependência. Sua autonomia que se funda na responsabilidade, que vai sendo assumida". Esse aspecto, sempre relevante a cada etapa de elaboração do Curso, torna-se decisivo quando se refere a um povo marcado por forte repressão, num país recém-independente e que vai reconstruindo sua própria história - política, econômica e, principalmente, socioeducacional. 


\section{Visitas às escolas dos professores integrantes do CPI}

As visitas tinham como objetivo conhecer a realidade de condições de trabalho para avaliar e repensar as atividades do CPI, adotando a perspectiva de Freire (1978), quando realizava visitas pedagógicas aos Círculos de Cultura, em Guiné-Bissau:

[...] é interessante sublinhar que a nossa atitude, ao visitar os Círculos de Cultura, não era, de um lado, a de quem se inclinasse à superestimação do que fosse observado nem, de outro, a de quem, fixado em realidade concreta. Nem euforias incontidas diante de certos acertos, nem negativismos em face dos equívocos que fôssemos encontrar. $\mathrm{O}$ importante era ver o que se fazia, nas condições materiais limitadas que sabíamos existir, para, em seguida, ver o que se poderia fazer de melhor, nas mesmas condições, caso não fosse possível, de imediato, torná-las mais favoráveis. (FREIRE, 1978, p. 31).

As visitas foram realizadas em 28 Pré-Escolas de Díli, quando, também, eram entrevistados coordenadores e diretores. Além disso, todas as visitas aconteciam com a presença do líder dos monitores - fundamental para orientar a condução de questões administrativas e de decisões que precisavam ser tomadas para garantir o bom andamento do Curso. A opinião dessa liderança era sempre respeitada e discutida, pois, sendo uma autoridade timorense e competente, saberia resolver adequadamente problemas administrativos e, muitas vezes, pedagógicos da realidade local, pois essa liderança tinha vivência profissional voltada para a Pré-eEcola timorense desde o período indonésio. Essa parceria foi fundamental para a avaliação, o desenvolvimento e a continuidade do Curso.

Nessas visitas pedagógicas, pôde-se constatar muitos pontos positivos, como a manifestação da criatividade e atitudes pautadas na autonomia desses docentes que, em sua prática de sala de aula, constantemente reinventavam e/ou adaptavam atividades vivenciadas no Curso e perceber limitações para implementação de alternativas sugeridas durante o processo de formação docente, contribuindo para os ajustes necessários. Da mesma forma, também o memorial elaborado mensalmente pelos professores da Pré-Escola era um instrumento importante de avaliação e melhoria.

\section{Os memoriais de formação}

O memorial é um texto narrativo em que se registram momentos marcantes da trajetória acadêmica e profissional ou ainda de experiências vivenciadas em um curso específico. Para Severino (2007, p. 245), “o memorial constitui uma autobiografia configurando-se como uma narrativa simultaneamente histórica e reflexiva". Trabalhou-se, aqui, com o memorial de formação, entendido 
também como uma estratégia pedagógica, utilizada como instrumento de investigação e acompanhamento do processo de formação.

O memorial preserva a vivência do esquecimento e contribui para a sistematização do fazer e refletir diário, exercitando a memória pessoal e social. Nas palavras de Carvalho e Corrêa (2012, p. 2), “narrar é ressignificar. E todas as ressignificações e versões são válidas e legítimas”. Sendo assim, ao produzir o memorial, no caso do professor em formação, tem-se mais uma oportunidade de repensar suas ações, refletir sobre elas e melhorar sua prática.

\section{O uso do memorial no CPI}

O memorial foi adotado como um dos instrumentos de registro e avaliação do CPI, exclusivamente para a turma do nível avançado, que consistia em um texto narrativo em que os participantes deveriam registrar, mensalmente, as atividades que julgassem mais relevantes, descrevendo de que forma contribuíram (ou não) para seu progresso no aprendizado da LP e/ou para sua vida profissional.

A avaliação desses memoriais ocorria, primeiramente, de maneira autoavaliativa; posteriormente, em dupla com um colega e, por fim, com o professor, procurando atender ao que Freire (2011, p. 63) ensina sobre o processo avaliativo: “O ideal é que cedo ou tarde, se invente uma forma pela qual os educandos possam participar da avaliação. É que o trabalho do professor é o trabalho do professor com os alunos e não do professor consigo mesmo". Entende-se que adotar a avaliação dos memoriais de forma partilhada coaduna-se com o processo de construção coletiva do Curso. Essa metodologia, apesar de dificuldades iniciais, teve resultados bastante positivos.

A escolha dos quatro memoriais aqui apontados como amostragem considerou o fato de seus autores terem ingressado no Curso em 2008 e permanecido até outubro de 2010, além de serem destacadamente participativos e de terem atuado como monitores. Como categorias de análise, elegeram-se:

1. impressão dos professores quanto à contribuição do CPI ou de atividades realizadas durante o seu processo para fluência na comunicação em LP;

2. conscientização da importância do CPI para a formação docente. 
Categoria 1 - A impressão dos professores quanto à contribuição do CPI ou de atividades realizadas durante o seu processo para fluência na comunicação em LP

[...] sinto que este curso é boa para continuar a aprender o português, porque com este curso posso aumentar a capacidade de falar português e podemos ter um futuro melhor como docente da pré-escola. As matérias que recebemos, como histórias, canções e outras também já ensinei nas escolas e gosto muito, eu gosto muito de participar no curso da língua portuguesa porque ajuda-me para a modificação do ensino e comunicação oral e também escritas e mais outras. (Memorial do informante $2)^{4}$.

No mês de setembro tivemos muitas actividades aulas da língua portuguesa instrumental que ajudam mais a nossa experiência da língua portuguesa que agora continuamos a aprender e nós terminando eu sinto-me muito contente neste curso por que aprendi muitas coisas. (Memorial do informante 4).

Em relação à contribuição do CPI para a melhoria da fluência em LP, dentre os informantes selecionados, dois deles, como se vê acima, destacaram a importância que o Curso teve para a continuidade da sua aprendizagem da LP. Ambos passaram 24 anos (período indonésio) sem estudar o português e com o CPI puderam utilizar o que traziam dessa língua na memória, regatar elementos esquecidos e avançar na aprendizagem e domínio da LP. O informante 2, por exemplo, após relatar os benefícios do Curso para a prática pedagógica, aponta a importância do CPI para a melhoria da sua comunicação oral e escrita em LP. Esses foram dois aspectos que, ao longo do curso, foram recorrentemente trabalhados, com a utilização de metodologia diversificada, a fim de minimizar dificuldades naturais do aprendizado e de fluência numa língua.

O trecho a seguir ilustra ter sido o recurso ao memorial uma estratégia que contribuiu para o desenvolvimento da oralidade e da escrita:

Agora falo da memória [memorial] que é um grande valor para mim, com a ajuda do curso da língua portuguesa instrumental, o memorial é uma escrita que faz com que eu possa ter um possibilidade para fazer um registro da minha própria experiência. Com ajuda do memorial a professora pode identificar como está aprendendo a língua de cada participante do curso de língua portuguesa durante esse tempo do curso. Para mim acho que a memória ajuda muito para falar e na escrita posso relembrar das palavras que muitas vezes esqueci. (Memorial do informante 2).

O trecho anterior, além de ratificar o auxílio do memorial para a reflexão da experiência como professor em formação, evidencia seu papel também para um desempenho satisfatório da prática comunicativa, tanto oral quanto escrita em Português. Além disso, por meio dos memoriais, percebe-se, 
por exemplo, aspectos do Curso que efetivamente interferiam na melhoria da vivência em sala de aula, por meio de relatos da implementação de atividades experienciadas no CPI e, posteriormente, replanejadas e reinventadas para serem desenvolvidas com as crianças da Pré-Escola.

Percebeu-se que o uso de memoriais no CPI foi uma das atividades que não só trouxe benefícios para os cursistas, mas também se constituiu como importante documento de registro do processo de construção e conclusão do curso. Aponta-se, ainda, que, apesar de o memorial ter sido uma atividade proposta somente a partir de fevereiro de 2010, os textos apontam para fatos ocorridos desde o início do Curso.

\section{Categoria 2 - Conscientização da importância do CPI para a formação docente}

Agora eu estou muito contente neste curso porque reflete na minha capacidade prática professional de aprendizagem e eu estou muito contente também porque aprendi muitas coisas que anteriormente não tinha nada pra mim, agora as actividades já apliquei para os alunos e eles gostaram muito nestes actividades que eu apresentei para eles, por isso eu também fico muito satisfeita, que o resultado do meu curso ajuda a desenvolver a minha capacidade de aprendizagem. (Memorial do informante 4).

Dentre os quatro informantes selecionados, dois explicitamente afirmam que o CPI influenciou positivamente a sua atuação docente. No relato do informante 4, acima, o cursista reflete sobre a oportunidade de participar de um treinamento que favoreceu o desenvolvimento da sua aprendizagem. Demonstra, ainda, satisfação e motivação na sua vivência profissional devido a alguns aspectos do Curso que facilitaram o seu trabalho em sala de aula com seus alunos.

[...] também outros grupos para contar as brincadeiras do Timor que ainda não estão escritas e podemos produzir livros de brincadeiras de tradicionais de Timor-Leste. Estas atividades que a professora deu são muito boas para poder produzir também mais livros de historias que eu ouvia quando era criança pode ajudar os professores para ensinar nas pré-escolas, com esse esforço da professora sinto que os professores vão ter capacidade para desenvolver bem os seus ensinos. (Memorial do informante 2, grifo nosso).

No trecho acima, cogita-se a possibilidade de produção de livros de histórias infantis e de brincadeiras tradicionais timorenses. Ao analisar os benefícios dessa atividade para a sua formação como participante do CPI, o informante escreve na primeira pessoa do plural, certamente se referindo à sua participação como integrante do grupo de monitores, quando contribuía com a formação dos 
professores das demais turmas. Sendo assim, ele avalia a importância da sua experiência no Curso e de que forma essa vivência poderia ajudar na formação docente de outros. Esse relato possibilitou-lhe refletir na perspectiva do crescimento coletivo e não do individual, destacando o valor da produção de livros timorenses não somente para ele, mas também para os demais professores "nas pré-escolas". O educador percebe, portanto, o seu papel social ao integrar um grupo que desenvolveu um material que será útil para os demais colegas de trabalho na sua atuação profissional, estabelecendo, assim, uma relação direta entre o CPI e sua atuação como docente. $\mathrm{O}$ registro que foi feito, em português e em tétum, das histórias que os professores ouviam na infância e das brincadeiras tradicionais timorenses, constitui-se em material rico para auxiliar no resgate da memória cultural do país.

Apesar desses quatro informantes não mencionarem em seus memoriais, foi possível perceber o progresso dos cursistas quanto à compreensão auditiva em LP, verificada, por exemplo, quando recorremos ao uso de canções infantis em LP: algumas brasileiras, atualmente muito comuns e bem aceitas naquele contexto, e muitas canções portuguesas - uma contribuição dos professores que as guardavam na memória de infância. Algumas versões de canções infantis em tétum foram traduzidas para a LP, num trabalho criativo e lúdico, que contou com a participação entusiasmada dos professores.

\section{Considerações finais}

Imagem 5 - Início do CPI fevereiro de 2008

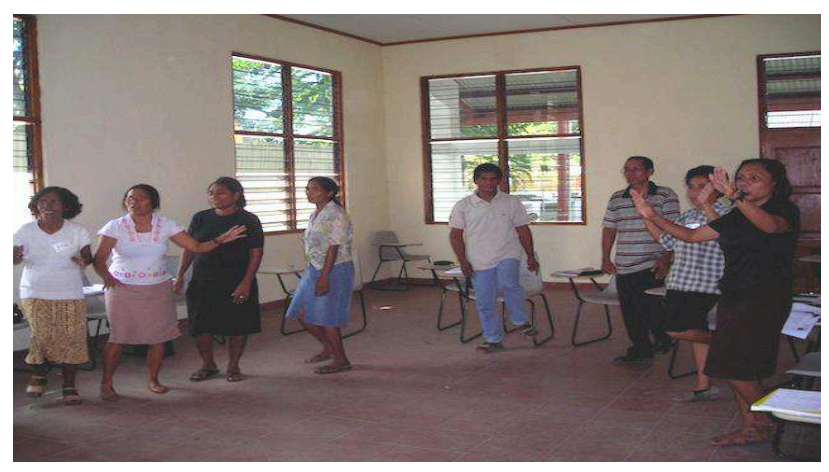

Fonte: Márcia V. Cavalcante, 2008.

\section{Imagem 6 - Encerramento do CPI em outubro de 2010}

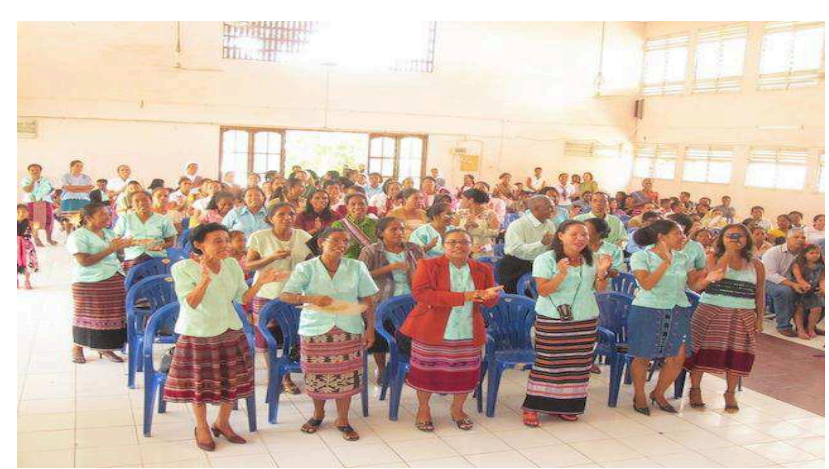

Fonte: Márcia V. Cavalcante, 2010.

Inserido no âmbito dos Estudos Lusófonos (numa perspectiva que valoriza a cultura e a variedade linguística de cada país de língua oficial portuguesa), voltada para o ensino de LP e formação de professores, em uma perspectiva freireana, a experiência relatada mostra como o ensino e a difusão do português em Timor-Leste deve ser encarado como uma ação que considere aspectos 
multilinguísticos e multiculturais - maneira pela qual o aprendizado da língua pode acontecer com maior facilidade e de forma mais significativa. Além disso, devem-se considerar os interesses gerais do público-alvo (no caso, composto basicamente por professores do ensino pré-escolar), agregando ao processo de ensino-aprendizado da LP, contribuições para o avanço da sua prática pedagógica cotidiana.

Nesse processo, destacam-se, ainda, como fatores que favoreceram o desenvolvimento da comunicação oral e escrita dos participantes: a ênfase à musicalidade, tão representativa do universo cultural e identitário timorense; a adoção de abordagem lúdica na metodologia do curso, adequando-se à realidade da Educação Pré-Escolar timorense e a elaboração de versão de canções em português que já existiam em tétum e que foram aplicadas aos alunos da pré-escola.

Registra-se como outro ponto favorável do CPI mudanças para a carreira docente dos profissionais que participaram do Curso. Em 2010, quando o Curso foi validado pelo INFORDEPE, alguns dos professores do nível avançado, já monitores, pelo nível muito bom atingido na proficiência em LP e pelos trabalhos significativos desenvolvidos em suas escolas, foram convidados pelo ME/Timor a ministrarem um curso de Formação Nacional, voltado para professores do ensino PréEscolar dos demais Distritos do país, atuando como multiplicadores. Essa oportunidade dada pelo ME/Timor possibilitou aos monitores do CPI compartilhar conhecimentos com professores que vivenciam realidades diversas e específicas de cada região de Timor-Leste: "quem ensina aprende ao ensinar e quem aprende ensina ao aprender”, diria Paulo Freire (2011, p. 25).

Em 2013, levando em consideração a proficiência em LP adquirida por aqueles professores nos anos anteriores e a validação do CPI pelo INFORDEP, a maioria dos integrantes do CPI ingressou no Curso de Licenciatura do Departamento Formação de Professores de Ensino Básico da Faculdade de Educação da Universidade Nacional de Timor Lorosa'e. Os professores que não possuíam o Ensino Secundário puderam participar de um Curso complementar modular, com créditos equivalentes ao Bacharelado, organizado pelo INFORDEP. Com isso, esses professores terão acesso à Universidade outro sinal de que o CPI também proporcionou novas oportunidades profissionais e possibilidades de ascensão em relação à vida acadêmica.

Destacamos como essenciais contributos para a aprendizagem da LP e para a prática pedagógica dos cursistas: (1) a relação estabelecida entre o tétum e o português, desde o início do Curso; (2) o reconhecimento e a valorização da variedade do português timorense. Nesse contexto, uma das estratégias que nos ajudou a perceber concretamente a importância do conhecimento do Tétum para 
o aprendizado da LP foi a elaboração de materiais pedagógicos bilíngues, durante as oficinas, visando tanto a aprendizagem da LP quanto sua utilização nas aulas da Pré-Escola. Outra estratégia desenvolvida a partir dos trabalhos nas duas línguas foi propor atividades que visassem ampliar o vocabulário do português, com empréstimos desta língua já incorporados ao tétum. Isso possibilitou a compreensão de algumas dificuldades dos alunos quanto à questão ortográfica e para conscientizá-los de que já dominavam muitas palavras da LP absorvidas pelo tétum. Conforme Carvalho (2004, p. 12):

[...] partir do léxico mais próximo [...], na perspectiva da aprendizagem de línguas como meio de multiculturalidade, intercâmbio entre povos, é sempre um avanço dos aprendentes, no sentido da universalidade do mundo de referência e dos itinerários de alguns itens lexicais na sua circulação/inclusão em diversas línguas, mesmo sem afinidade genética alguma. E sobretudo, constitui estratégia de celeridade no processo de aprendizagem.

O uso da língua tétum como ponte para o ensino do Português no CPI mostrou-se eficaz e que deve ser considerado em qualquer curso que se realize em Timor-Leste, buscando semelhanças e diferenças existentes entre esses dois idiomas, facilitando o processo ensino-aprendizagem de LP naquele país. Nessa direção, cooperantes estrangeiros que desejem atuar em Timor-Leste precisam ter noções básicas do tétum, segundo Costa (2012, p. 219): “o formador [internacional] deve saber minimamente, a língua tétum e a cultura do povo a fim de capacitar o docente timorense a conhecer e identificar semelhanças e diferenças que existem entre o português e o tétum ou as outras línguas locais". Certamente, a compreensão do tétum pode apontar caminhos para a metodologia a ser utilizada, já que algumas dificuldades no aprendizado da LP ocorrem exatamente pelas diferenças estruturais existentes entre os dois idiomas.

Nessa mesma perspectiva, o linguista australiano Geoffrey Hull, em 2001, já nos alertava que:

[...] se os estrangeiros residentes em Timor-Leste se habituarem a comunicar na sua própria língua com os locais, certamente que não farão o mínimo de esforço para aprender o tétum. Se esta prática se generalizar, levaria a uma rápida dominação cultural, como a que havia no período colonial. (HULL, 2001, p. 49).

A dominação cultural apontada não se daria apenas pela ausência do aprendizado do tétum. Outro aspecto que podemos abordar como forma de domínio cultural seria a imposição de qualquer variedade de português que desconsidere a existência das peculiaridades do português falado em Timor-Leste. Com efeito, a experiência aqui relatada indica que o respeito à norma do português utilizado no espaço timorense, muito próximo da variedade europeia, já vai dando mostras de suas 
particularidades, pelo contexto multilinguístico em que vive. Respeitar esse uso particular da LP em Timor-Leste - cujos estudos sociolinguísticos ainda são incipientes - foi um fator do CPI que contribuiu para que os cursistas vissem o aprendizado da LP como significativo e relevante, o que nos remete a Lourenço (2001, p. 111): “se quisermos dar algum sentido à galáxia lusófona, temos de vivêla, na medida do possível, como inextricavelmente portuguesa, brasileira, moçambicana, cabo-verdiana ou são-tomense", ao que complementamos "e timorense":

Em Timor-Leste, como em cada um dos outros espaços de sua oficialidade - Angola, Brasil, Cabo Verde, Guiné-Bissau, Moçambique e São Tomé e Príncipe - a língua portuguesa conhece e constrói a sua própria história. E, por isso, está muito longe de poder ser tratado como um idioma uniforme. É com essa perspectiva que se deve encarar o "desafio" da língua portuguesa em Timor-Leste: está-se diante de mais uma variedade do português. (BRITO, 2010, p. 194).

Respeitar as experiências particulares, os valores distintos, a especificidade cultural e suas aproximações, o modo próprio de vivenciar a realidade e a visão de mundo que cada comunidade do universo lusófono fixa na variedade do português é a perspectiva a adotar para o entendimento da construção de uma possível identidade lusófona. (BRITO, 2013, p. 123).

Faz-se necessário, por fim, o reconhecimento, a descrição e a legitimação da variedade do Português em uso, por parte dos timorenses e dos cooperantes lusófonos no país - especificamente àqueles voltados às questões linguísticas e educacionais - como contributos para o fortalecimento da identidade nacional timorense.

\section{Notas}

${ }^{1}$ Este artigo trata-se de reflexão a partir de recorte da dissertação de mestrado de Marcia Vandineide Cavalcante (2013), desenvolvida sob orientação de Regina Pires de Brito, defendida junto ao Programa de Pós-Graduação em Letras da Universidade Presbiteriana Mackenzie.

${ }^{2}$ Genericamente, o conceito de espaço lusófono abrange o conjunto de identidades linguístico-culturais, que pela língua portuguesa se faz representar tanto nos países em que é língua oficial (compondo a Comunidade dos Países de Língua Portuguesa - CPLP: Angola, Brasil, Cabo Verde, Guiné-Bissau, Moçambique, Portugal, São Tomé e Príncipe e Timor-Leste) quanto nas muitas comunidades dispersas pelo mundo (Galiza, na Espanha; Austrália, Canadá, China, Estados Unidos, França, Índia, Japão, Suíça, entre outros).

${ }^{3}$ Atualmente, encontra-se em tramitação uma legislação cujo currículo não contemplará a utilização do Português na Educação Pré-Escolar de Timor-Leste.

${ }^{4}$ Os trechos extraídos dos Memoriais são transcrições que reproduzem exatamente os originais. 


\section{REFERÊNCIAS}

BRITO, Regina H. P. Temas para a compreensão do atual quadro linguístico de Timor-Leste. Ciências e Letras, Revista da Faculdade Porto-Alegrense, Porto Alegre, n. 48, p. 175- 194, jul./dez. 2010.

BRITO, Regina H. P. Pontos para uma caracterização do português em Timor-Leste. Avanços em Ciências da Linguagem, Santiago de Compostela, 2012.

BRITO, Regina H. P. Língua e identidade no universo da lusofonia: aspectos de Timor-Leste e Moçambique. São Paulo: Terracota, 2013.

CARDOSO, Luís. Crónica de uma travessia: a época de Ai-Dik-Funam. 2. ed. Lisboa: Publicações Dom Quixote, 2002.

CARVALHO, Luana de A.; CORRÊA, Hércules T. Memorial de Leitura: uma possível estratégia pedagógica nos currículos dos cursos de formação de professores. In: SIMPÓSIO INTERNACIONAL DE ENSINO DE LÍNGUA PORTUGUESA, 2., 2012, Uberlândia. Anais... Uberlândia, MG: UFU, 2012.

CARVALHO, Maria José A. de. Aprendizagem do léxico português e empréstimos timor, restante sudeste asiático e Japão. Estudos de línguas e culturas de Timor-Leste. Díli, 2004.

CAVALCANTE, Márcia Vandineide. Ensino de língua portuguesa para professores da Pré- Escola: uma experiência em Timor-Leste. 2013. 143f. Dissertação (Mestrado em Letras) - Universidade Presbiteriana Mackenzie, São Paulo, 2013.

CORTE-REAL, Benjamim A.; BRITO, Regina H. Pires de. Aspectos da política linguística de TimorLeste: desvendando contracorrentes. In: MARTINS, Moisés et al. (Org.). Comunicação e lusofonia. Porto: Campo das Letras, 2006. p. 123-132.

COSTA, Luís. A língua. Fator de identidade nacional leste-timorense. In: BASTOS, Neusa B. (Org.). Aspectos linguísticos, culturais e identitários. São Paulo: EDUC, 2012.

FREIRE, Paulo. Cartas à Guiné- Bissau: registro de uma experiência em processo. Rio de Janeiro: Paz e terra, 1978.

FREIRE, Paulo. Política e educação: ensaios. 7. ed. São Paulo: Cortez, 2003.

FREIRE, Paulo. Pedagogia da Autonomia. São Paulo: Paz e Terra, 2011.

HULL, Geoffrey. Timor-Leste: identidade, língua e política educacional. Lisboa: Instituto Camões, 2001.

LOURENÇO, Eduardo. A Nau de Ícaro. São Paulo: Companhia das Letras, 2001. 

primeiras décadas do século XX no Brasil

SEVERINO, Antonio Joaquim. Metodologia do Trabalho Científico. 23. ed. São Paulo: Cortez, 2007.

SOUSA. Domingos de. Colibere. Lisboa: Lidel, 2007.

THOMAZ, Luís F. R. Babel Loro Sa'e: O problema linguístico de Timor-Leste. Lisboa: Instituto Camões, 2002.

TIMOR-LESTE. Lei n ${ }^{0}$ 14, de 29 de outubro de 2008. Leis de Base da Educação. Jornal da República: publicação oficial da República Democrática de Timor-Leste, Díli, 29 out. 2008.

VASCONCELOS. Maria Lúcia C.; BRITO, Regina Helena P. de. Conceitos de educação em Paulo Freire. São Paulo: Vozes, 2006. 


\section{The Portuguese Language: teacher training and pre-school education in the East Timor context}

\begin{abstract}
Since the period of the United Nations Transitional Administration in East Timor, many are the cooperation programs from Brazil and Portugal aimed at the dissemination and teaching of Portuguese Language in that country. As an example, the Teacher Training Program and the Portuguese Language Teaching in East Timor, in the Portuguese acronym) promoted by the Coordination for the Improvement of Higher Education Personnel. In this sense, at the confluence of the areas of education (using Paulo Freire's perspective) and Lusophone Studies, after a brief background of the Portuguese Language situation in East Timor (in the colonial period and during the Indonesian rule), this article, based on memorials prepared by participants of the Instrumental Portuguese Course (CPI), inserted into the Portuguese Language Instrumental Teaching Project, analyzes some aspects of the work carried out under this course, aimed at teachers of Dili preschool. We point out here the perception of educators in relation to the CPI's contribution and to the activities proposed which address both the fluency of expression in Portuguese and, mainly, a prolific teaching practice and the teachers' awareness process on the need for mastering the Portuguese language.
\end{abstract}

Keywords: Portuguese Language Teaching. Teachers Training. East Timor.

Márcia Vandineide Cavalcante

E-mail:marciacalva@hotmail.com

Regina Pires Brito

E-mail:rhbrito@mackenzie.br
Lengua Portuguesa: la formación de los docentes y la educación preescolar en TimorOriental

\section{Resumen}

Desde el período de Administración de Transición de las Naciones Unidas en Timor-Leste, ha habido varios programas de cooperación Brasil y Portugal para la difusión y la enseñanza del portugués en ese país. Es el caso, por ejemplo, del Programa de Formación de Profesorado y la Enseñanza de la Lengua portuguesa en Timor-Leste, patrocinado por la Coordenação de Aperfeiçoamento de Pessoal de Nível Superior. En este sentido, a partir de los ámbitos de la Educación (perspectiva de Paulo Freire) y de los estudios de la lengua portuguesa, después de una breve reseña de la situación lingüística en Timor-Leste (en el período colonial y durante el gobierno de Indonesia), este artículo, basado en registros desarrollados por los participantes del Curso de Portugués Instrumental (CPI), en el contexto del Proyecto Enseñanza del Portugués Instrumental, examina algunos aspectos de las actividades realizadas durante el curso, dirigido a profesores de pre-escolar de Dili. Se destacan aquí la percepción de los educadores en relación a la contribución del IPC y las actividades propuestas, llevando en cuenta tanto la fluidez de expresión en portugués y, sobre todo, la idea de una práctica docente productiva y el proceso de sensibilización de los docentes sobre la necesidad de un buen conocimiento de la lengua portuguesa.

Palabras claves: Lengua portuguesa. Formación de Docentes. Timor-Oriental.
Enviado em: 21/6/2015

Aprovado em: 13/3/2016 